\title{
Ectopic Pheochromocytoma: Does the Rule of Tens Apply?
}

\author{
R. Madani $\cdot$ M. Al-Hashmi $\cdot$ R. Bliss $\cdot$ \\ T. W. J. Lennard
}

Published online: 18 December 2007

(c) Société Internationale de Chirurgie 2007

\section{Erratum to: World Journal of Surgery \\ DOI: 10.1007/s00268-006-0608-1}

In the above-mentioned article, published in World Journal of Surgery volume 31/number 4, pp 849-854, 2007, the figure captions were mis-labeled. Below please find the correct captions:

Figure 1. Meta-iodobenzyl guanidine (MIBG) scan of mediastinal pheochromocytoma
Figure 2. Magnetic resonance imaging scan of a mediastinal pheochromocytoma (arrow)

Figure 3. Computer tomography scan of a neck pheochromocytoma (arrow)

Figure 4. Locations of ectopic pheochromocytoma

We regret this error.
The online version of the original article can be found under doi: 10.1007/s00268-006-0608-1

R. Madani - M. Al-Hashmi - R. Bliss · T. W. J. Lennard ( () Department of Surgery, Royal Victoria Infirmary, Queen Victoria Road, Newcastle upon Tyne,

Tyne and Wear NE1 4LP, UK

e-mail: t.w.j.lennard@ncl.ac.uk

R. Madani

Department of Surgery, Whittington Hospital, Magdale Ave, London, UK

e-mail: ranamadani@doctors.org.uk 